\title{
Solution for Sealant Dosage Form
}

National Cancer Institute

\section{Source}

National Cancer Institute. Solution for Sealant Dosage Form. NCI Thesaurus. Code C149928.

Liquid sterile preparation consisting of a solution intended for the preparation of a sealant. 